\title{
Identidad nacional, historia de elite y prensa en Costa Rica. Los funerales de Estado del Lic. Cleto González Víquez (1937) y del Lic. Braulio Carrillo Colina (1972)
}

DOI: http://dx.doi.org/10.5377/koot.v0i8.5848

Chester Urbina Gaitán

Catedrático e investigador Universidad Nacional Heredia, Costa Rica chesterurbina@yahoo.com

URI: http://hdl.handle.net/11298/380

\section{Resumen}

El funeral de Estado del Lic. Cleto González Víquez (1937) le permitió a los gobernantes de turno de Costa Rica ensalzar la figura de este ex mandatario como referente moral y patriótico. Se exaltaron sus cualidades como su amor por el trabajo, al estudio, al hogar, el respeto a la democracia, su humildad, la entrega y sacrificio por la patria. Esto pretendía reforzar los valores sobre los cuales se asentaba la identidad nacional costarricense; y en última instancia, invisibilizar la desigualdad y la explotación de clase que prevalecía. Por otra parte, la llegada de los restos mortales de don Braulio Carrillo al país en 1972 fue utilizada por el gobierno de José Figueres Ferrer para transmitir una visión de la historia y de la política de tipo elitista, donde el Estado es la construcción directa y única de la clase dominante y se construye para regular y encauzar el conflicto social. Los intelectuales que escribieron sobre este hecho lo hicieron sin asidero histórico, con el fin de transmitir un sentimiento de pertenencia nacional y de sacrificio por la patria.

Palabras clave: Cleto González Víquez, Braulio Carrillo, Estado, identidad nacional costarricense, prensa.

\begin{abstract}
The state funeral of Cleto González Víquez (1937) allowed the contemporary leaders of Costa Rica to praise the character of this former president as a moral and patriotic icon. His exalted qualities included his love for work, for study, for home, and his respect for democracy, his humbleness, dedication and sacrifice for the country. This with the intention to reinforce the values on which the Costa Rican national identity was based. In the end, the real intention was to
\end{abstract}

\footnotetext{
* El autor agradece los comentarios a una versión preliminar de este artículo al M. Sc. José Manuel Cerdas Albertazzi.
} 
obscure the inequality and exploitation from the ruling class. On the other hand, the arrival of the mortal remains of Don Braulio Carrillo to the country in 1972, was used by the government of Jose Figueres Ferrer to convey a vision of the history and the politics from an elitist standpoint, where the State is defined as the direct and unique creation of the ruling class. This was built to regulate and channel social conflict. The intellectuals who wrote about this fact did it without any historical bases since they intended to communicate a feeling of national identity and sacrifice for the country.

Keywords: Cleto González Víquez, Braulio Carrillo, State, Costa Rican national identity, press

\section{Exaltación moral, identidad nacional y prensa en Costa Rica. El funeral de Estado del Lic. Cleto González Víquez (1937) A}

La creación del Estado moderno necesitó la construcción de una compleja red de control de los sectores dominados, coordinando las labores de la policía, del cuerpo médico y de las instituciones educativas (Foucault, 2000 y González, 1996, 22). Con respecto a la construcción de los Estados-nación, Hobsbawm señala que en este proceso los estados se sirven de instrumentos - tales como la ciudadanía, educación, ejército, etc. - para transmitir su idea de nación hacia el resto de sectores sociales (Hobsbawm, 1991). Empero, las ideas de nación también reciben la influencia de los sectores subalternos, quienes reelaboran y adaptan a sus condiciones particulares lo que las elites intelectuales, económicas y políticas producen para legitimarse en el poder.

La nación moderna está vinculada al nacimiento del capitalismo, donde el sistema educativo es fundamental en la reproducción de la fuerza laboral necesaria para este sistema económico. Para Ernest Gellner el Estado necesita crear una lengua y una cultura nacional (Gellner, 1983, 34). Con el monopolio de la educación oficial el Estado busca instaurar la homogeneidad cultural y la lealtad a un sistema político. Miroslav Hroch ha indicado que, los dos principales factores que llevaron al proceso de construcción de naciones fueron: por un lado la necesidad de un creciente número de individuos, de encontrar un nuevo objeto de identificación individual, tras la pérdida de sus tradicionales vínculos sociales y políticos con la aldea, el señor feudal o el gremio"; y por otro, el hecho objetivo de que regiones cada vez más distantes fueran puestas en contacto entre sí a través de los adelantos en el transporte, la expansión de los mercados, la industrialización [...] que produjeron una mayor movilidad territorial y social y un aumento de la comunicación social'(Hroch, 1990, 106). De todo esto surgirá un nuevo concepto de naciones, que para Benedict Anderson son ante todo "comunidades imaginadas" donde el periódico, junto con la novela, fueron medios a través de los cuales fue posible representarse el tipo de comunidad imaginada que es la nación (Anderson, 1993, 15). 
La construcción de una identidad nacional en Costa Rica se comienza a registrar en las crónicas que viajeros extranjeros dejaban a su paso por el país. Rafael Francisco Osejo exaltó en 1834, la estabilidad política y la permanencia del sistema constitucional de gobierno. Sobre los habitantes nacionales señaló que eran "pacíficos y laboriosos" (Zelaya, 1971: 80). Esta imagen nacional se consolidó en las últimas décadas del siglo XIX, donde sobresale lo que Joaquín Bernardo Calvo indicó sobre las características étnicas de los costarricenses, al hacer referencia a que la "raza nacional" era blanca, homogénea, sana y robusta, y unida a estas buenas condiciones físicas se encontraban las de la laboriosidad, su afán por la cultura y prosperidad y su espíritu de orden y amor al trabajo (Calvo, 1887: 34; Revista Estudios, 2003: 73-104).

Según Díaz, hacia el segundo lustro de la década de 1880, los gobernantes liberales intentaran llevar adelante la construcción cultural de la nación costarricense, basados en imágenes discursivas, ya presentes en la mentalidad políticas seis décadas atrás. Una sociedad pacifica, disciplinada, deseosa del progreso y, por ende, trabajadora, blanca y homogénea, será la visión que intentaran consolidar en el imaginario popular. Al mismo, tiempo se rescata la Campaña Nacional contra los filibusteros, se modela de forma que tal que permita sobresalir a Juan Santamaría en ella, y se integra en el discurso oficial la figura del héroe humilde que se inmola por la patria en un acto incendiario contra su enemigo (Díaz Arias, 2005, 69-70).

Para 1937 la burguesía nacional se encontraba madura, con un sofisticado sistema de control social, donde la educación y la higiene social - aparte de otros mecanismos habían desempeñado un papel fundamental en la búsqueda de la consolidación de una identidad nacional mediante la invención de la nación. (Fischel, 1987; Padilla Elizondo, 1995; Taracena A., Arturo y Piel, Jean, 1995, 75-85, y, Gil Zúñiga, 1999).

En 1929 la vulnerable economía de agro exportación costarricense - basada en el cultivo del café y del banano - sufrió los embates de la Gran Depresión. La crisis económica afectó al Estado costarricense con un grave déficit fiscal entre 1929 y 1936. Los más perjudicados fueron los trabajadores urbanos y los trabajadores de la bananera, base del Partido Comunista de Costa Rica, fundado en 1931. Entre las medidas que tomó el Estado para enfrentar la crisis, está la del financiamiento de obras públicas, con el fin de bajar el desempleo, la cual se triplicó entre 1932 y 1939, y caracterizó al mandato de León Cortés Castro (1936-1940) como el gobierno del “cemento y la varilla" (Molina, y Palmer, 2004, 72).

En medio de este contexto de crisis económica surge a la palestra política el Partido Comunista de Costa Rica, liderado por un pequeño grupo de jóvenes estudiantes de derecho y cuya base estaba compuesta principalmente por artesanos y obreros en las ciudades y por trabajadores de las fincas de banano, se caracterizó por un discurso muy confrontativo ("clase contra clase") durante los años 1931-1935, periodo en el que debió superar un intento inicial de ilegalización, en el cual tuvo algunos choques violentos con la policía y en el que dirigió la huelga bananera de 1934. (Molina 
Jiménez, 2006 En: http://www.scielo.org.mx/scielo.php?script=sci_arttext\&pid $=\mathrm{S} 140592742006000300008 \& \operatorname{lng}=$ es \&nrm=iso Consultado el 10 de agosto de 2015). Cabe destacar que es en el segundo gobierno de Cleto González Víquez, que se le impidió al Partido Comunista participar en las elecciones presidenciales de febrero de 1932 (Molina Jiménez, 2007, 72-73. En: Inter.c.a.mbio. Año 4. No. 5. En: file://C:/Users/pc01/Desktop/Dialnet-RicardoJimenezYLosComunistas EnLaCostaRicaDeLaDecad-5089076.pdf Consultado el 10 de agosto de 2015). Fundamentado en todo lo anterior, es que se justifica el objetivo del presente artículo de estudiar como el funeral de Estado del ex Presidente Cleto González Víquez de 1937, fue utilizado por los gobernantes de turno y por la prensa costarricense, para transmitir un sentimiento de pertenencia nacional.

El jueves 23 de setiembre de 1937 falleció el ex Presidente de Costa Rica Lic. Cleto González Víquez, quien gobernó el país en dos períodos: de 1906 a 1910 y de 1928 a 1932. Su deceso hizo que se decretara duelo nacional por tres días y sus honras póstumas tuvieron carácter de funeral de Estado. Los funerales del ex mandatario se realizaron el sábado 25 de setiembre del año antes citado, el cortejo fúnebre acompañó de la casa de habitación hasta el Palacio Nacional la caja mortuoria. Dentro del recinto parlamentario desde su llegada hasta las nueve horas, el cadáver fue puesto en capilla ardiente haciéndole guardia de honor los diputados del país. Estaba presentes el Presidente de la República Lic. León Cortés Castro, su gabinete, la Corte Suprema de Justicia, el Cuerpo Diplomático, altos funcionarios civiles y militares, los familiares del fallecido y un nutrido público. El primero en dar su oración fúnebre fue el Presidente Cortés Castro, quien resaltó que don Cleto era un ejemplo de imitar para los costarricenses por su firme voluntad en el estudio y en trabajo, por la ingénita bondad de sus costumbres, por su devota consagración al hogar, por la firmeza de sus convicciones ciudadanas, por su amor a las instituciones democráticas y al régimen de la República (Diario de Costa Rica, 1937, 5).

Asimismo, el Presidente Cortés habló sobre la extracción social del Lic. González Víquez: "De origen humilde, nació en el seno mismo del pueblo, en modesta población de la provincia de Heredia surgió de la llanura y se hizo a sí mismo, con la constancia de su esfuerzo, con su acerada voluntad, con su infatigable trabajo,... (Diario de Costa Rica, 1937, 5). Lo señalado por don León acerca de los orígenes del extinto ex jefe de Estado no es cierto, debido a que don Cleto provenía de una reconocida familia de cafetaleros, por lo que se pretendía eliminar la existencia de la lucha de clases en el país (Stone, 1993, 265 y 270).

Prosiguió en el uso de la palabra, el Presidente del Congreso, el Lic. Juan Rafael Arias quien alabó al señor González Víquez por su sencillez y gran capacidad de estudio, principalmente de la historia nacional. Además, don Juan Rafael ensalzó la labor pública del extinto: “...puede decirse que el señor González Víquez ejercía siempre un alto ministerio social que por sus afanes a favor de los municipios y de la beneficencia y por su deseo constante de servir, su oficina era una antorcha que 
iluminaba todos los senderos y su mano sabia apartaba los peligros, de todos los caminos;... (Diario de Costa Rica, 1937, 7). El último en tomar la palabra fue el Lic. Luis Dávila, presidente de la Corte Suprema de Justicia, quien al igual que sus antecesores resaltó las cualidades morales de don Cleto, las cuales hicieron de él un benemérito de la Patria, y el padre de los ancianos y enfermos menesterosos (Diario de Costa Rica, 1937, 7).

Una vez que concluyeron los discursos anteriores, los restos de don Cleto fueron llevados a la Catedral de San José, donde se ofició una solemne misa oficiada por el Arzobispo de San José, Monseñor Rafael Otón Castro. A las 11 de la mañana terminaron las exequias fúnebres en la catedral e instantes después en el atrio de la misma, a la salida de la misma el Gobernador de la provincia de San José en representación de la municipalidad capitalina, enfatizó que don Cleto cuando fue presidente de la misma se preocupó por su ornato, su higienización, su comodidad y su progreso (La Tribuna, Sábado 25 de setiembre de 1937, 7). Acerca de la política de higiene del Lic. González Víquez esta se basaba en su visión racista de la sociedad costarricense, donde concebía al país como una sociedad blanca y homogénea, sin indígenas y sin poblaciones de origen africano, por lo que debía preservar esa particularidad para seguir existiendo como nación. Don Cleto creía que en vez de fomentar la inmigración de extranjeros. Costa Rica debía fomentar la "autoinmigración" es decir, llevar al máximo la producción y la reproducción nacional por medio de una baja en la tasa de mortalidad infantil y la implementación de medidas moral y biológicamente sanitarias en toda Costa Rica. Esta visión racista se extendió entre las clases populares costarricense a principios del siglo XX y de que en las décadas de 1910 y 1920 fue acogida entre obreros y artesanos (Díaz Arias, David. "Pequeños patriotas y ciudadanos: Infancia, nación y conmemoración de la independencia en Costa Rica, 1899-1932". En: Araucaria. Vol.13. No.25. 2011. p.103. En: http://www.redalyc.org/pdf/282/28217003006.pdf Consultado el 10 de agosto de 2015.

Luego tomó la palabra el Lic. Carlos Lara en representación del Colegio de Abogados de Costa Rica, puso al extinto mandatario como ejemplo de entrega y sacrificio por el país: “...y fue su constante preocupación por los costarricenses repitiéramos su nombre con cariño como habremos de hacerlo siempre al recordar que él como los hijos de la antigua Grecia antes de pertenecerse a sí mismo, se perteneció a la patria, a la que todo ciudadano le debe el tributo de sus bienes, de su valor, de su talento y de sus desvelos...(La Tribuna, Sábado 25 de setiembre de 1937, 7).

Para cerrar estos discursos continúo en el uso de la palabra el presidente de la Junta de Asistencia Social de San José, el Lic. Alberto Echando Montero, quien aparte de resaltar las cualidades personales del difunto, recordó que él era el padre de la democracia y la más firme columna de la república (La Tribuna, sábado 25 de setiembre de 1937, 7). Posteriormente, los restos del Lic. González Víquez fueron trasladados al Cementerio capitalino donde fueron enterrados. El titulo atribuido a don 
Cleto como padre de la democracia, es inmerecedero debido a que la forma en que llegó al poder durante su primer mandato fue ilegal. Según Iván Molina, para las elecciones de primer grado de 1905, los partidos de oposición denunciaron que el partido oficial, cuyo candidato era González Víquez, pagaba gastos y jornales y regalaba almuerzos para conseguir votos. Las autoridades amenazaban con dar de alta a los que no se sumaran al partido oficial, y que los hacendados obligaban a sus peones a apoyar a dicho partido. Pese a todas estas presiones don Cleto solo obtuvo el 41 por ciento de los electores, lo que obligó al gobierno de Ascensión Esquivel a hacer uso de la fuerza para asegurar el triunfo del candidato oficial (Molina, Iván. "Fraude electoral y cultura popular en Costa Rica (1902-1948)". p.7. Ponencia presentada al XX International Congress of the Latin American Studies Association (1719) de abril de 1997), Guadalajara, México).

Sobre los discursos periodísticos emitidos por la prensa costarricense en torno a la muerte del ex mandatario González Víquez, La Tribuna publicó el viernes 24 de setiembre de 1937, en su sección "Día a día", un artículo titulado "Sobre la tumba de don Cleto", donde la muerte del ex mandatario sirvió para reforzar los lazos identitarios de los costarricenses: "Pues bien acaba de entregar su vida al Señor un santo de la democracia, un santo del patriotismo, un santo de la igualdad fraterna. La voz unánime de este medio millón de habitantes que forman la patria costarricense tiembla de emoción sentimental (La Tribuna, Viernes 24 de setiembre de 1937, 2)". Concluye el texto señalando que, sobre la tumba de don Cleto no hay que levantar una estatua ni un monumento. Solamente había que colocar sobre la lápida una sola expresión nacional: el mapa de Costa Rica (La Tribuna, Viernes 24 de setiembre de 1937, 2). Acerca del uso del mapa Benedict Anderson ha señalado que la masiva reproducción del mapa-logo conseguirá, ciertamente, que el contorno del país se haga inmediatamente reconocible y penetre, de este modo, en la imaginación popular, formando un poderoso emblema de los nacionalismos (Anderson, 1993, 245).

\section{Historia de elite y de olvido. La llegada a Costa Rica de los restos mortales del Lic. Braulio Carrillo Colina (1972)}

Según Manuel Calderón es posible comprender y explicar la formación del Estado a partir de procesos sociales caracterizados porque "no progresan linealmente a posiciones mejores, sino que avanzan retomando el pasado, deshaciéndolo a veces, negando conquistas o reelaborándolos en una dirección distinta o en varias simultáneas Un Estado no se forma a partir de un hecho casual, tampoco es producto de "grandes hombres", ni debemos considerarlo como una creación exclusiva de las "clases dominantes"; tampoco es simplemente acaparado por ellas. De manera que no se debe determinar la formación del Estado al margen de procesos sociales ni encasillarlos como instrumento de clase (Botey Sobrado, 2000, 184). Se entenderá por Estado la condensación material de relaciones de fuerza entre clases, grupos, actores y fuerzas, quienes posibilitan una unidad nacional en momentos históricos concretos. 
Unidad que se expresa en un conjunto de instituciones, que sirven como medio para la lucha de intereses comunes de los miembros de una sociedad; es decir, visualizamos el Estado como un espacio de lucha política y no exclusivamente como regulador del conflicto social (Botey Sobrado, 2000,185).

La obra del Lic. Braulio Carrillo Colina (1800-1844) en la formación del Estado en Costa Rica es fundamental, durante su primera administración (1835-1837) impone un impuesto territorial y la formación de registros de la propiedad. Regula la venta de terrenos municipales. Suprime días feriados y prohíbe las procesiones, y deroga la Ley de la Ambulancia que estipulaba que la capital estaría por períodos en las ciudades de Alajuela, Heredia, San José y Cartago. Esto lleva a la Guerra de la Liga donde se define que la capital estaría en San José. Su segunda administración (1838-1842) es fecunda en cuanto a aportes en la formación del Estado: recuperó la soberanía política de Costa Rica, al separarla de la República Federal de Centroamérica, dio estímulos a la producción y al comercio, impulsó la privatización de la propiedad, promovió la actividad cafetalera, creó el primer arancel de aduanas del país, creó el Reglamento General para la Hacienda Pública y los códigos Civil, Penal y de Procedimientos. Todo lo anterior le ha valido a Carrillo los calificativos de "arquitecto del Estado costarricense" o "el gobernante de la acumulación originaria (de capital) de Costa Rica". (Botey Sobrado, 2000, 197-199).

Después de finalizada la Guerra Civil de 1948, el Estado adopta una serie de medidas reformistas que tienen como objetivo el mejoramiento de la calidad de vida de amplios sectores de la población, lo que da lugar a un constante crecimiento de la matrícula, sobre todo en la enseñanza primaria, pero también en la secundaria y la universitaria; un aumento de la expectativa de vida y la disminución de la mortalidad infantil, un mejoramiento de las redes de agua potable y alcantarillado. Esto dio como resultado una mejora de las condiciones higiénicas de la población; un crecimiento constante de los salarios reales, una distribución del ingreso más equitativa, sobre todo en los sectores medios de la población, que aumentó del 34 \% al 44 \% (Cuevas, 1995: 8).

Fundamentado en todo lo anterior, es que el presente artículo tiene como objetivo estudiar como la llegada de los restos mortales del ex Jefe de Estado Lic. Braulio Carrillo en 1972, fue utilizada por el gobierno de José Figueres Ferrer (1970-1974) y por la prensa nacional para transmitir un sentimiento de pertenencia nacional y una visión de la historia costarricense de tipo elitista, donde se pretende perdonar y olvidar los abusos y atropellos cometidos por Carrillo y otros destacados ex mandatarios.

Los restos mortales del Lic. Braulio Carrillo Colina llegaron al país el lunes 15 de mayo de 1972. El Presidente de la República José Figueres Ferrer fue a 


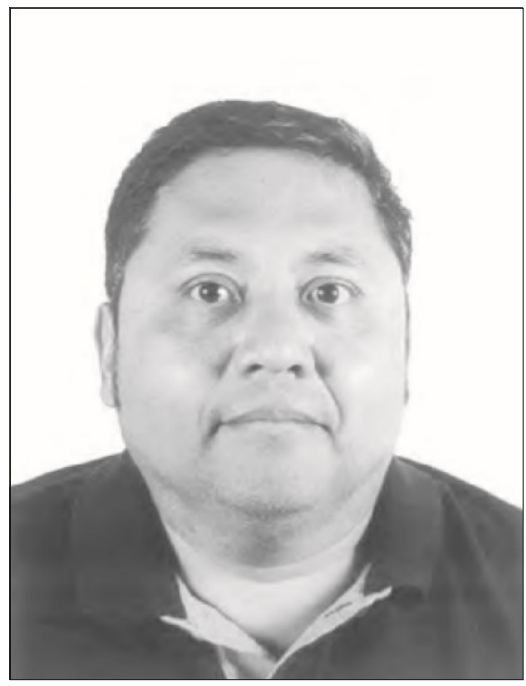

Chester Urbina Gaitán

recibirlos junto a una comitiva especial y dijo: "Es una necedad hablar de los errores de don Braulio Carrillo. ¿Qué le importan a Sansón, o a la historia, las opiniones de los liliputienses? Señalarle errores al hombre que veía un siglo adelante, al hombre que veía desfilar los siglos, es no saber lo que se habla. Don Braulio Carrillo gobernó a Costa Rica pensando en relación al presente y al futuro (La República, 1972, 1)". Con todo esto don José criticaba a los que juzgaban con puntos de mira supuestamente "intrascendentes" la obra política de don Braulio. Sobresale en el discurso de don José una visión elitista de la política y de la cultura, la cual se comentará más adelante.

Luego, al dirigirse a la delegación salvadoreña que vino a hacer entrega de los restos del Lic. Carrillo, don José - en un tono conciliatorio sobre el asesinato de Carrillo refirió: "Amigos salvadoreños, cuando murió Carrillo en soledad no era costarricenseQuien lo mató no era salvadoreño. Ambos representaban el bien y el mal. Ambos representaban en la sociedad y la humanidad de Centroamérica, simplemente el bien y el mal del pueblo centroamericano (La República, 1972, 28)". Más adelante se analizara que esta visión dualista - de comparar a don Braulio con el bien - no explica la realidad de su gestión política, ya que gobernó en forma ilegal e ilegítima.

Después del recibimiento oficial, los restos de don Braulio fueron llevados hacia la Asamblea Legislativa. A la una de la tarde el féretro ingresó al Salón de los Ex Presidentes, donde permaneció toda la noche recibiendo el homenaje de los tres Poderes de la República, de los estudiantes y la Fuerza Pública. En este recinto parlamentario se dieron los discursos del Ministro de Cultura, Juventud y Deportes, Lic. Alberto Cañas; del Presidente de la Corte Suprema de Justicia, Lic. Fabio Baudrit; del Presidente de la Corte Suprema de Justicia de El Salvador, Dr. Armando Arias y 
del Presidente de la República, don José Figueres. El Lic. Cañas al comentar el gobierno de don Braulio acotó: “...y cuando el hombre fue el ciudadano, el Licenciado, el Jefe de Estado Braulio Carrillo, lo que resta de él es esto que vivimos, esto que somos, esto que nos alberga, esta sociedad, este modo de vivir, esta Patria...Quiso legarnos una nacionalidad, y nos legó una nacionalidad. Quiso legarnos una soberanía y nos legó una soberanía. Quiso legarnos un Estado, y nos legó un Estado. Se salió bruscamente de la lista de gobernantes patriarcales, y fue el suyo el primer gobierno fuerte, y el primer gobierno que se propuso cambiar algo. Ahora vemos que lo que se propuso cambiar estaba mal, y que el cambio que introdujo estaba bien. Ahora sabemos que lo hizo persistió y fue valido; y que la patria se formó, a partir de su nombre, dentro de las líneas que el trazó (La República, 1972, 28)”.

Con respecto a lo señalado por don Alberto, debe aclararse que Carrillo solo crea algunos elementos para la formación del Estado; es decir, el Estado no se consolida con su poder; todas sus medidas se dan con el respaldo de militares en una situación de hecho, poniendo de manifiesto su naturaleza ilegítima. Durante el mandato de don Braulio, no se da la voluntad, menos la pertenencia, lo cual impide sostener la existencia de un Estado nacional. No existía voluntad ni pertenencia por vivir una situación de hecho bajo un clima de coacción y represión, clima que lo llevó a perder gran parte de su base de apoyo social (Botey Sobrado, 2000, 202). La construcción del Estado en Costa Rica fue un proceso donde no solo participó el Lic. Carrillo, sino que también recibió el aporte de otros grupos, clases y fuerzas sociales. Es cierto, que hubo continuidad en el proceso de construcción estatal, aunque también hubo retrocesos como la política de olvido hacia los abusos y crímenes de la dictadura de los Tinoco. Esta postura política era antidemocrática, ya que pretendía ocultar como la clase dominante costarricense usó la violencia del Estado para mantenerse en el poder e impedir que el electorado nacional fortaleciera el papel de los partidos políticos y el ejercicio de sus derechos ciudadanos (Bonilla Castro, Alejandro. "El retrato del recuerdo y el olvido. Políticas de conciliación, olvido y memorias emblemáticas de la dictadura de Federico Tinoco Granados (1917-1963)". En: Diálogos. Vol.16, No, 1 (2015). En: http://revistas.ucr.ac.cr/index.php/dialogos/ article/view/15379/17328 Consultado el 5 de agosto de 2015).

Asimismo, don Alberto continuó - en el mismo tono - señalando: "Ya vamos comprendiendo que las Patrias requieren de constructores y también de consolidadores...El liberalismo doctrinario e irreversible de un glorioso Doctor Castro, la visión impresionante de un Mora (¿es que vamos a condenarle porque se reeligió?), la decisión inquebrantable de un Guardia propuesto a abrirnos hacia los mares, el nacionalismo sin estridencias de un Yglesias que nos dio un ferrocarril nacional en un continente donde los ferrocarriles rara vez fueron nacionales. Y también la impresionante presencia de un Carrillo que vio una Costa Rica soberana, una Costa Rica con entidad de Estado fuerte... (La República, 1972, 29)". En el discurso del Lic. Cañas se vuelve a reiterar una visión elitista de la historia política, donde la nación es una construcción de la clase gobernante, no existe el aporte, la crítica, la reformulación 
y la impugnación de los sectores populares. Se pretende a la vez, que magnificar la labor política de los gobernantes "fuertes" del país, restarle importancia a los golpes de Estado, los abusos y atropellos que cometieron. Se destaca en el texto anterior un rompimiento con el discurso liberal decimonónico sobre la identidad nacional costarricense, el cual hacia el segundo lustro de la década de 1880, fue utilizado por los gobernantes liberales que intentaban llevar adelante la construcción cultural de la nación costarricense, basados en imágenes discursivas, ya presentes en la mentalidad políticas seis décadas atrás. Una sociedad pacífica, disciplinada, deseosa del progreso $\mathrm{y}$, por ende, trabajadora, blanca y homogénea, será la visión que intentaran consolidar en el imaginario popular. Al mismo, tiempo se rescata la Campaña Nacional contra los filibusteros, se modela de forma que tal que permita sobresalir a Juan Santamaría en ella, y se integra en el discurso oficial la figura del héroe humilde que se inmola por la patria en un acto incendiario contra su enemigo (Díaz Arias, 2005, 69-70).

En el discurso anterior de don Alberto existe una visión elitista de la cultura. Según Cuevas entre 1970 a 1978 Liberación Nacional articula un tipo de políticas culturales donde el pueblo solo debe consumir lo que hacen los productores de cultura especializados. Esta idea, encuentra su máxima expresión en la política gubernamental de extensión - o, como también se le llamó, de difusión o propagación - que ya se ha iniciado años antes desde las primeras iniciativas socialdemócratas en los años 50 y que será el ideario de las principales instituciones gubernamentales encargadas de impulsar la labor cultural. Quiere decir, que la concepción de cultura vehiculizada por los «hombres de letras de Liberación Nacional» y por el mismo José Figueres, que encuentra expresión en la política cultural del Estado en la década de 1970 y es caracterizada como parte de una idea «global del desarrollo» costarricense (Cuevas, 1995, 97-98). El por qué don Alberto no se refiere a la dictadura de los Tinoco (19171919) radica en que para él los costarricenses perdonan todos los delitos políticos, menos la traición. Según Bonilla, de ahí, remite a los generales Máximo Blanco y Lorenzo Salazar, gestores supuestos de la traición a Juan Rafael Mora Porras y olvidados de la historia (incluso su máxima gloria: la toma de los vapores en el río San Juan y que decidió la Campaña Nacional). Como Federico Tinoco fue traidor, Costa Rica no lo perdonó (¿o sí?) y por eso, el Congreso declaró nulos todos los actos de este gobierno y su existencia legal: "Blanco, Salazar y Tinoco son los tres hombres a quienes Costa Rica ha condenado al exilio, al olvido y al silencio. Y los dos primeros tuvieron otros, enormes méritos de que el tercero carece." (Bonilla Castro, 2013, 315).

En lo señalado por don José y don Alberto destaca una de las características fundamentales de los regímenes políticos del siglo XX, especialmente de los de tipo totalitario, ha sido su interés por los problemas derivados del conocimiento y la utilización del pasado, es decir, por el control y la manipulación de la historiografía y de la memoria (Todorov, 2002: 139). Sobre esto White apunta: "el grado en el que la historiografía sirve al sistema de domesticación y disciplinamiento de la sociedad", a través de la educación y la conmemoración, por ejemplo, ya que "su función ha sido, las más de las veces, disciplinar y adaptar la memoria ciudadana del pasado a lo que 
un grupo dominante en el poder exige de sus "sujetos" (Godoy, 2002:14). Lo dicho por don José y don Alberto nos pone ante un hecho político, donde la historia y el pasado costarricense son re-escritos y delimitados por las necesidades políticas del momento. Esta selección histórica pretendía articular una "historia oficial" con el fin de justificar el presente con una versión alterada y parcial del pasado.

Entre los artículos periodísticos que salieron a la luz con motivo de la llegada de los restos mortales del Lic. Braulio Carrillo, se tiene el que publicó don Francisco María Núñez miembro de la Academia de Geografía e Historia de Costa Rica, en el Diario de Costa Rica el lunes 15 de mayo de 1972 titulado: "El sentido humano de Braulio Carrillo", donde se destaca la labor política del extinto Jefe de Estado: "Impuso orden: combatió la vagancia y los vicios, con mano dura. Quizás se extralimitó, pero impulsado por el deseo de organizar una patria ejemplar. Pacífica, laboriosa, capaz de realizar su propio destino (Diario de Costa Rica, 1972, 3)". Más adelante señala: "Gobernó sin tener a su lado fuerzas militares. Vivió en el santuario de su hogar, solo; sin amigos. Con el pensamiento puesto en su patria, a la cual le dio códigos y señaló rumbos, con el afán de verla prosperar en paz (Diario de Costa Rica, 1972, 3)". En el texto de don Francisco se reitera un discurso elitista sobre la construcción del Estado, donde la gestión política de don Braulio generó un sentimiento de pertenencia nacional alrededor de elementos identitarios tradicionales como la paz y el trabajo de los costarricenses, lo cual como se ha visto, no es cierto. Tampoco es cierto que Carrillo haya gobernado sin usar la fuerza militar. Para Díaz, el triunfo de San José en la Guerra de la Liga (1835) les brindó a los líderes militares un protagonismo cada vez más importante en la elección de las autoridades políticas en los siguientes años. Es esta situación la que permite a las elites políticas de San José, en mayo de 1838, desconocer el gobierno de Manuel Aguilar (1837) y llamar al poder nuevamente a Braulio Carrillo (1838-1842). Las elecciones habían dejado de ser funcionales y el poder militar era ahora primordial para acceder a los puestos estatales. Carrillo se percate de esto y trata de organizar al ejército como medio de coerción, con el fin de tener una base de poder para desenvolverse. Es así como Carrillo centraliza las fuerzas militares en San José, disuelve la de las otras ciudades, otorga una ley constitutiva al ejército, aumenta el número de sus efectivos, lo apertrecha mejor al comprarle armas y municiones, le aumenta el salario a los soldados, conserva el sistema de privilegios españoles que le aseguraba al ejercito pensiones, premios y el fuero militar. Aparte de eso establece una Academia Militar (Díaz Arias, 2005, 28-29).

En el editorial del mismo periódico en la fecha antes citada, denominado "Braulio Carrillo hoy en Costa Rica", Julio Suñol destaca que la conducta férrea de don Braulio constituía garantía del mantenimiento del orden y de la paz para realizaciones superiores. Sugería que los centros educativos del país debían de dar a conocer la historia de la vida de Carrillo, quien solo tenía un pensamiento: "dar todo a Costa Rica a cambio de nada. Como debe ser (Diario de Costa Rica, 1972, 4)". Del párrafo anterior sobresale un discurso que Villena ha llamado "la economía moral del sacrificio", esto es importante porque se considera, desde los sectores conservadores, 
que la sociedad costarricense está atravesando por una "crisis de valores", por una etapa de dramática pérdida de valores y de sentimiento patriótico. Según este discurso los costarricenses estarían abandonando los míticos valores campesinos y serían cada vez menos sacrificados por la patria y solidarios entre sí (Villena, 2006, 136).

\section{Conclusión}

El funeral de Estado del ex Presidente Cleto González Víquez en 1937, le permitieron a los gobernantes de turno usarlo para transmitir un sentimiento de pertenencia nacional, al exaltar las cualidades personales del extinto mandatario como: su amor por el trabajo, al estudio, al hogar, el respeto a la democracia, su humildad, la entrega y sacrificio por la patria. Estas cualidades también fueron enaltecidas por la prensa nacional como elementos constitutivos de la identidad nacional costarricense. Asimismo, se alabó la labor de higienización social emprendida por González Víquez, la cual era parte de un sofisticado sistema de control social donde se buscaba transmitir un concepto de identidad nacional anclado a un proyecto cultural de nación que invisibilizaba las diferencias de clase.

La llegada de los restos mortales de don Braulio Carrillo al país en 1972 fue utilizada por el gobierno de José Figueres Ferrer para transmitir una visión de la historia y de la política de tipo elitista, donde el Estado es la construcción directa y única de la clase dominante y se construye para regular y encauzar el conflicto social. Tal visión es a nivel político antidemocrática, y tiene un carácter lineal, debido a que no toma en cuenta a otros protagonistas sociales y considera que la formación del Estado sigue un proceso lineal, donde no existen retrocesos ni atropellos ni abusos por parte de los que detentan el poder. Todo esto va en concordancia con la política cultural de elite del gobierno de Figueres. Tanto en lo dicho por don José como por don Alberto, sobresale el interés político por el control y la manipulación de la historiografía y de la memoria de los costarricenses, lo que pretendía articular una "historia oficial" con el fin de justificar el presente con una versión alterada y parcial del pasado.

Asimismo, en el discurso de don Francisco María Núñez se trata de explicar que, el gobierno de don Braulio transmitió un sentimiento de pertenencia nacional y se realizó sin la ayuda de los militares, lo cual no tiene ningún asidero histórico. En el discurso de don Julio Suñol se hace un llamado a que los centros educativos den a conocer la gestión política de don Braulio, lo cual debía motivar a que los costarricenses siguieran el ejemplo del prócer y se inmolaran por la patria. 


\section{Referentes bibliográficos}

\section{Periódicos}

Diario de Costa Rica. Sábado 25 de setiembre de 1937. Año XIX. No.5360.

La Tribuna. Viernes 24 de setiembre de 1937. Año XVIII. No.5076.

La Tribuna. Sábado 25 de setiembre de 1937. Año XVIII. No.5077.

Diario de Costa Rica, Lunes 15 de mayo de 1972, Año. LXXXVI, No.19.994. La República, Martes 16 de mayo de 1972, Año XXI, No.6848.

\section{Libros}

Anderson, Benedict. Comunidades imaginadas. Reflexiones sobre el origen y difusión del nacionalismo. México D.F.: Fondo de Cultura Económica. 1993.

Botey Sobrado, Ana María, coordinadora,Costa Rica, Estado, economía, sociedad y cultura: desde las sociedades autóctonas hasta 1914, San José: Editorial de la Universidad de Costa Rica: Cátedra de Historia de las Instituciones de Costa Rica. 2000.

Calvo, Joaquín Bernardo. República de Costa Rica. Apuntamientos geográficos, estadísticos e históricos. San José: Imprenta Nacional. 1987.

Cuevas, Rafael. El punto sobre la I. Políticas Culturales en Costa Rica (19481990), San José: Ministerio de Cultura, Juventud y Deportes. 1995.

Díaz Arias, David. Construcción de un estado moderno: política, Estado e identidad nacional en Costa Rica, 1821-1914. San José: Editorial de la Universidad de Costa Rica. 2005.

Fernández Bravo, Álvaro (comp.). La invención de la nación. Lecturas de la identidad de Herder a Homi Bhabha. Buenos Aires: Manantial. 2000.

Fischel, Astrid. Consenso y represión: Una interpretación socio-política de la educación costarricense. San José: Editorial Costa Rica. 1987.

Foucault, Michel. Vigilar y castigar. Décima segunda edición. Madrid: Siglo XXI. 2000.

Gellner, Ernest. Nations and Nationalism. Ithaca: Cornell University Press. 1983.

Godoy, C., Historiografía y Memoria colectiva. Tiempos y Territorios, Madrid, Miño y Dávila Editores. 2002.

Hobsbawm, Eric. Naciones y nacionalismo desde 1780. Barcelona: Editorial Crítica. 1991.

Molina, Iván y Palmer, Steven. Historia de Costa Rica. Breve, actualizada y con ilustraciones. San José: Editorial de la Universidad de Costa Rica. 2004.

Stone, Samuel. El legado de los conquistadores. Las clases dirigentes de América Central desde la conquista hasta los Sandinistas. San José:

EUNED. 1993. 
Urbina Gaitán, Chester. Identidad nacional, historia de elite y prensa en Costa Rica. Los funerales de Estado del Lic. Cleto González Viquez (1937) y del Lic. Braulio Carrillo Colina (1972). Págs. 9-23.

Taracena A., Arturo y Piel, Jean comps. Identidades nacionales y Estado moderno en Centroamérica. San José: Editorial de la Universidad de Costa Rica. 1995.

Todorov, T., Memoria del mal, Tentación del bien. Indagación sobre el siglo XX, Barcelona: Península. 2002.

Villena Fiengo, Sergio, Golbalización. Siete ensayos heréticos sobre fútbol, identidad y cultura, San José: Ediciones Farben / Grupo Editorial Norma. 2006.

Zelaya Goodman, Chester J. El bachiller Osejo. Tomo II. San José: Editorial Costa Rica. 1971.

Artículos de revistas impresas

Díaz Arias, David. "Una Fiesta del Discurso: vocabulario político e identidad nacional en el discurso de las celebraciones de la independencia en Costa Rica, 18481921". En: Revista Estudios. No.17. San José: Universidad de Costa Rica, Centro de Estudios Generales, 2003.

Hroch, Miroslav, "How much does nation formation depend on nationalism?". Eastern European Politics and Society. Vol.4. No.1. 1990.

Artículos de revistas electrónicas

Díaz Arias, David. "Pequeños patriotas y ciudadanos: Infancia, nación y conmemoración de la independencia en Costa Rica, 1899-1932". En: Araucaria. Vol.13. No.25. 2011. En: http://www.redalyc.org/ pdf/282/28217003006.pdf Consultado el 10 de agosto de 2015.

Bonilla Castro, Alejandro. "El retrato del recuerdo y el olvido. Políticas de conciliación, olvido y memorias emblemáticas de la dictadura de Federico Tinoco Granados (1917-1963)". En: Diálogos. Vol.16, No, 1 (2015). En: http://revistas.ucr.ac.cr/index.php/dialogos/article/view/15379/17328

Consultado el 5 de agosto de 2015.

Molina Jiménez, Iván. "Catolicismo y comunismo en Costa Rica (1931-1940)". Desacatos. No.22. México. Sep./Dic. 2006. En: http://www.scielo.org. $\mathrm{mx} /$ scielo.php?script $=$ sci_arttext\&pid=S1405-92742006000300008\&lng $=$ es\&nrm=iso

Molina Jiménez, Iván. "Ricardo Jiménez y los comunistas en la Costa Rica de la década de 1930". En: Inter.c.a.mbio. Año 4. No.5. (2007). En: file:///C:/ Users/pc01/Desktop/Dialnet-RicardoJimenezYLosComunistasEnLaCost aRicaDeLaDecad-5089076.pdf

Ponencias 
Gil Zúñiga, José Daniel. "Controlaron el espacio hombres, mujeres y almas 18801941". Seminario: "Fin de Siglo XIX e identidad nacional en México y Centroamérica". Museo Histórico-Cultural Juan Santamaría.

Alajuela, Costa Rica, 11-14 de mayo de 1999.

Molina, Iván. "Fraude electoral y cultura popular en Costa Rica (1902-1948)". Ponencia presentada al XX International Congress of the Latin American Studies Association (17-19) de abril de 1997), Guadalajara, México.

Tesis

Bonilla Castro, Alejandro de Jesús. "El retrato del recuerdo y el olvido: Políticas de conciliación, olvido y memorias emblemáticas del dictadura de Federico Tinoco Granados (1917-1963)”. Tesis en Historia. Universidad de Costa Rica. 2013.

Padilla Elizondo, Isabel. 1995. La educación como agente legitimador del estado costarricense. Tesis de Licenciatura. Escuela de Historia. Universidad Nacional de Costa Rica. Heredia. Costa Rica. 


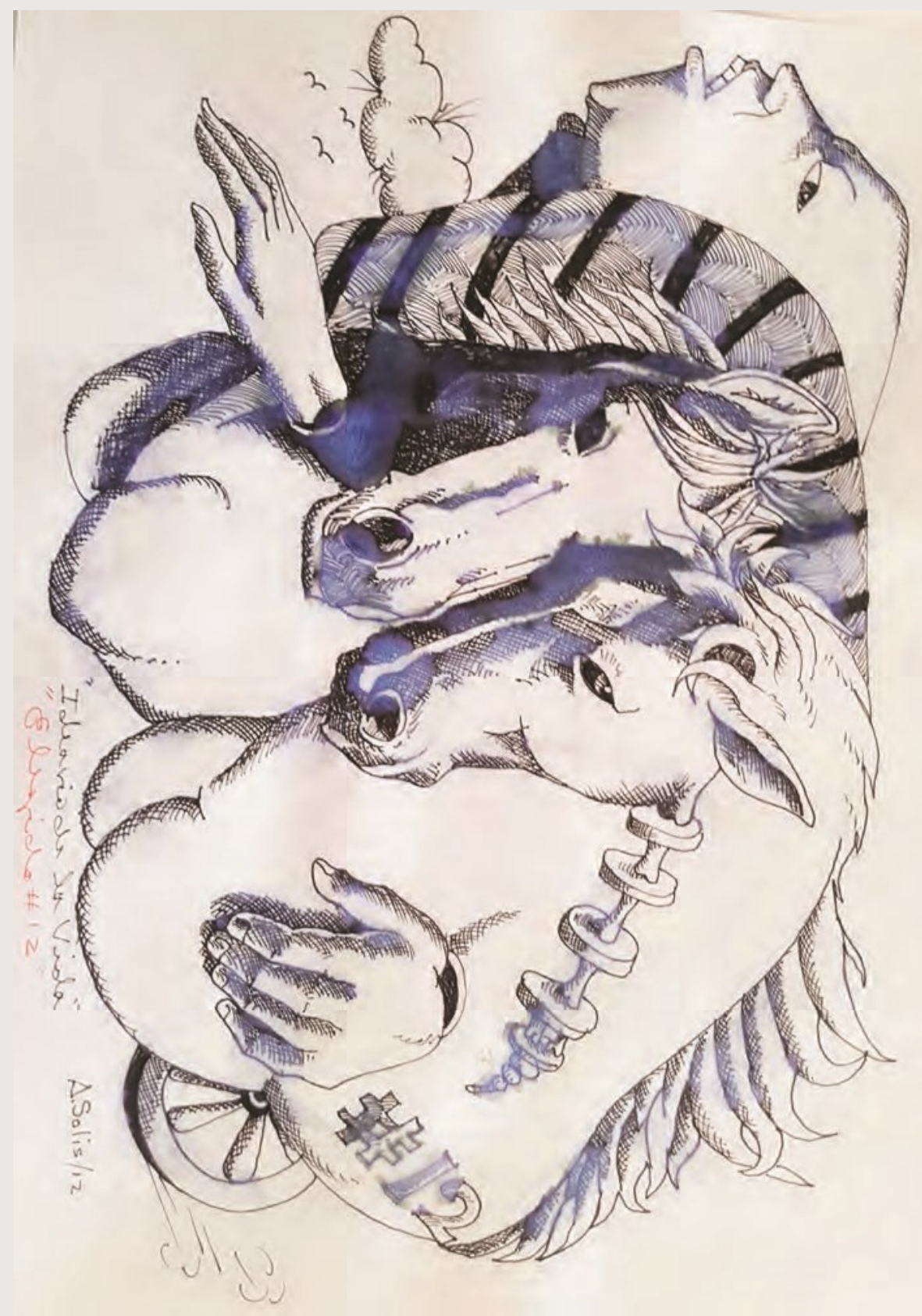

Armando Solis 